\title{
Thermoplastic Starch Films Added with Dry Nopal (Opuntia Ficus Indica) Fibers
}

\author{
Fabrizio Scognamiglio ${ }^{1}$, Daniele Mirabile Gattia ${ }^{2}$, Graziella Roselli ${ }^{3}$, Franca Persia ${ }^{2}$, \\ Ugo De Angelis ${ }^{2}$ and Carlo Santulli ${ }^{4, *}$ \\ 1 Technologies and Diagnostics for Conservation and Restoration Laboratory, School of Science and \\ Technology, University of Camerino, Via Pacifici Mazzoni 2, 63100 Ascoli Piceno, Italy; \\ fabrizio.scognamiglio@unicam.it \\ 2 Department of Sustainability SSPT-ENEA—Casaccia Research Center, Via Anguillarese 301, 00123 Rome, \\ Italy; daniele.mirabile@enea.it (D.M.G.); franca.persia@enea.it (F.P.); ugo.deangelis@enea.it (U.D.A.) \\ 3 Chemistry Division, School of Science and Technology, University of Camerino, Via S. Agostino 1, \\ 62032 Camerino, Italy; graziella.roselli@unicam.it \\ 4 School of Architecture and Design, University of Camerino, viale della Rimembranza, \\ 63100 Ascoli Piceno, Italy \\ * Correspondence: carlo.santulli@unicam.it; Tel.: +39-380-652-2232
}

Received: 19 September 2019; Accepted: 4 November 2019; Published: 19 November 2019

check for updates

\begin{abstract}
Dry fibers coming from garden waste, originating from Opuntia ficus indica, were introduced in amounts of either 8 or $16 \mathrm{wt} \%$ into a self-produced thermoplastic starch (TPS) based on potato starch and glycerol. Thermal (differential scanning calorimetry, DSC), mechanical (tensile tests), and morphological characterization with scanning electron microscopy (SEM) and performing energy-dispersive X-ray spectrometry (microanalysis) were carried out. The results indicated that the uneven distribution and variable geometry of fibers introduced led to a reduction of tensile stress and strain with respect to pure TPS. However, the positive effects of prolonged mixing and increased thickness were highlighted, which suggest the fabrication of the composite could be improved in the future by controlling the manufacturing procedure.
\end{abstract}

Keywords: thermoplastic starch; Opuntia fibers; tensile tests; differential scanning calorimetry; SEM morphology

\section{Introduction}

Opuntia ficus indica, also referred to as "nopal", is a plant that is used in Italy, as in many countries around the Mediterranean Sea, for its ornamental value and is therefore widely available, especially in the central and southern part of the country. Most Opuntia plants are used in Southern Italy for the production of Indian figs. According to data supplied from the Istituto Nazionale di Statistica (National Institute for Statistics) (ISTAT), 750,000-900,000 quintals per year of fruits are produced. In this case, plants need to be pruned during winter with the removal of cladodes (i.e., flattened leaf-like stems). In addition, the Opuntia is used as a garden plant in a much larger area in Italy to delimit allotments and prevent intrusion, thanks to its spines. The removal of worn-out cladodes from the plant does in any case generate some amount of waste. In particular, cladodes include mucilage, which is starting to receive some interest as an industrial hydrocolloid [1], and cellulosic fibers, which could have a dietary value when fresh [2], yet once dried are normally dumped or incinerated. It is possible, though, to use these fibers to reinforce a polymer matrix, especially aiming at improving its tensile properties. In particular, the use of a biopolymer, such as a starch-glycerol thermoplastic (TPS), could be suitable for this purpose. The use of cellulosic fibers for this purpose is widely documented 
in the literature; for example, those extracted from eucalyptus leaves bring a substantial increment of the tensile performance of the TPS [3]. Normally, this type of vegetable waste is introduced in the matrix in the form of short and randomly oriented fibers; therefore, it is important to ensure that a sufficient aspect ratio (length/diameter) of the fibers is obtained to have some reinforcement effect.

Passing to Opuntia cellulose content, a possibility that was investigated is to extract its crystalline fraction by obtaining nanocellulose fibers. This is of great interest, although it involves a quite intensive chemical treatment of the waste material, resulting in a limited yield of the process [4]. Aiming at the production of films, also, the extracted waste is acceptable in diameter to the orders of tens of microns, comparable with commonly used plant fibers and using the aforementioned waste as close as possible to the as-received state [5]. In general, it could be considered that due to the large presence of salts, such as calcium oxalates, forming real networks on the fibers, these could have a significant tensile strength, which is also at the origin of these being able to withstand the weight of the whole cladode, the leaf-reservoir typical of these plants [6,7].

Discarding worn-out parts of the nopal plant in the normal situation of garden waste collection involves a quite long and hardly controllable time before pruning and during storage, with the result that the vegetable waste becomes naturally dry. Some studies on other vegetable waste, such as New Zealand's flax (Phormium tenax), used discarded fibers as filler in a biopolymer matrix, offering promising evidence of the suitability of this practice to fabricate biocomposites [8]. Of course, a possibility would be the acquisition and processing of a typical biopolymer, such as poly(lactic acid) (PLA); another way would be though the synthesis of TPS, with the added possibility of also using waste for it (e.g., expired corn starch). This has been defined in other works as the production of "Do-It-Yourself (DIY) bioplastics", mainly based on waste, and proved adapted to some uses, such as packaging or even biomedical applications, despite the limitation of hardly being able to be used above the gelling temperature of starch (e.g., around $\left.80{ }^{\circ} \mathrm{C}\right)[9,10]$.

The present investigation concerns mechanical (tensile) and morphological investigation of TPS films reinforced with nopal dry fibers in view of their possible application in the field of plant fiber composites. These have seen a very large application in recent decades as replacement materials for some traditional composites, like fiberglass, for their inherent sustainability, especially when produced with a biopolymer matrix [11]. In particular, there is continuous search for other plant fibers for these applications, especially with local origin, so as to use them in a "zero-km" approach [12]. Some applications have already been performed on Opuntia fibers, either in an oil-based thermoset matrix, such as epoxy [13], or in a commercial biopolymer, such as in the case of poly(lactic acid) (PLA) [14]. The aim of this study is to analyze the self-production of the matrix in the form of thermoplastic starch and the direct processing of waste from Opuntia, to be used as filler, taking into account the inherent variability of its properties. The influence of two factors for production will be investigated (i.e., the amount of fibers and the stirring time of gelling solution obtained).

\section{Materials and Methods}

\subsection{Fibers}

The fibers used for the study were available after long storage at Agenzia nazionale per le nuove tecnologie, l'energia e lo sviluppo economico sostenibile (ENEA), in Anguillara, Italy, originating from some Opuntia plants, which were cut for garden area maintenance on the site. An example of the waste material as-received is depicted in Figure 1. To obtain the fibers, the material obtained was first cleaned with compressed air and brush, after which they were washed and brushed, then cut in small pieces, in the order of $20 \mathrm{~mm}$ or so. After this, they were sonicated in distilled water for $30 \mathrm{~min}$, then dried in an oven at $70{ }^{\circ} \mathrm{C}$ for $24 \mathrm{~h}$ and finally mashed in ball mill for $2 \mathrm{~h}$. The final sizes of the fibers obtained were not higher than $1 \mathrm{~mm}$ in length, and with very variable aspect ratios, from close to 1 , therefore in powder form, to others with up to 10-20. 


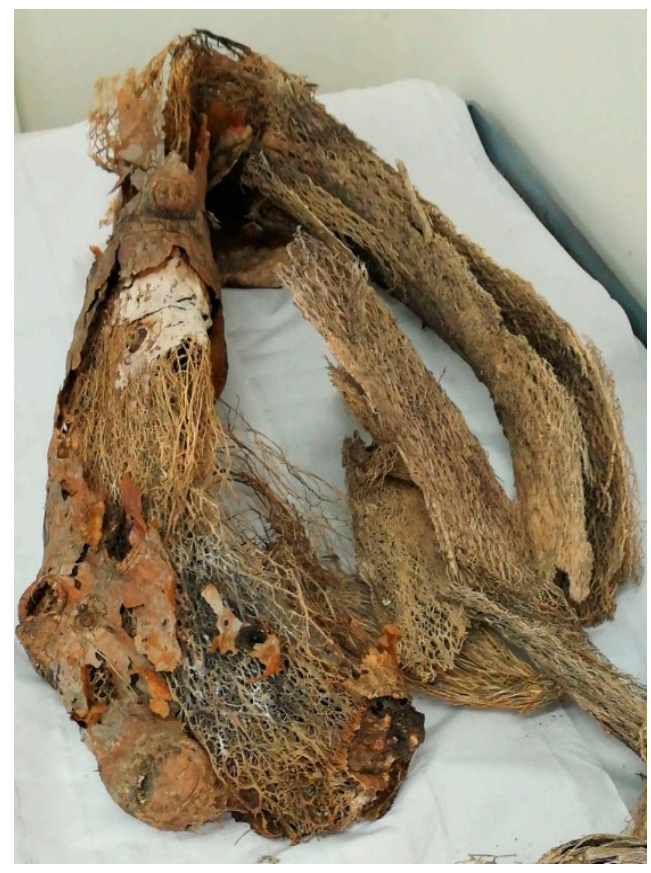

Figure 1. Fibrous waste material as received.

\subsection{Films Preparation}

A thermoplastic starch (TPS) film, aiming at a thickness of approximately 120 microns, was prepared using $10 \mathrm{~g}$ of sieved potato starch and $4 \mathrm{~mL}$ of glycerol, reagent grade, therefore with $99.5 \%$ purity, in $400 \mathrm{~mL}$ of distilled water. The solution was stirred manually for approximately $10 \mathrm{~min}$, until its appearance was uniform. It was then subsequently poured in an uncovered steel mold with surface covered in Teflon, to ease demolding, and then kept there for an hour at $70{ }^{\circ} \mathrm{C}$, and finally at $45^{\circ} \mathrm{C}$ overnight. No pressure was purposely applied for production for simplicity and to observe which degree of consolidation was obtained in TPS and their composites in this way. A similar procedure was followed in [9].

After producing the TPS film for comparison, three types of films with added dry nopal fibers were produced, always following the above procedure, but proceeding to the addition of fibers, as follows:

- Composite A: contains an amount of fibers equal to $16 \mathrm{wt} \%$ of the total starch + glycerol content. In this case, the stirring lasted for $1 \mathrm{~h}$.

- Composite B: contains an amount of fibers equal to $16 \mathrm{wt} \%$ of the total starch + glycerol content. In this case, the stirring lasted for $5 \mathrm{~h}$ to increase homogeneity.

- Composite C: produced as composite A, but with an amount of fibers equal to $8 \mathrm{wt} \%$ of the total starch + glycerol content.

The three different composites were produced to understand which effect appeared to be predominant on the properties of the composite between the one due to the amount of fibers introduced and the other due to the stirring time. For this reason, a significantly large variation in the amount of fibers introduced between $A$ to $B$ and $C$ composites, and in the stirring time between $A$ to $C$ and B composites.

\subsection{Films Preparation}

The measurements carried out involve, apart from basic morphological characterization, such as film thickness measurement, other sounder methods of analysis, including, in particular:

- Optical microscopy and scanning electron microscopy (SEM) of the films as received, to evaluate their morphology and after tensile tests, to study the fracture surfaces. The SEM apparatus used 
is a Zeiss EVO MA15. Using SEM, qualitative analyses of the elements present on the surface were also carried out by EDS (energy-dispersive X-ray spectrometry).

- Tensile tests were performed using a Testometric model MICRO350 $5 \mathrm{kN}$ system, with a $50 \mathrm{~N}$ load cell. Tests were carried out in displacement control mode at a cross-head velocity equal to $2 \mathrm{~mm} / \mathrm{minute}$. The dimensions of the samples are shown in Figure 2.

- Differential scanning calorimetry (DSC) to evaluate the evolution of films and composites behavior with temperature by heating at a rate of $10{ }^{\circ} \mathrm{C} / \mathrm{min}$, from 25 to $180^{\circ} \mathrm{C}$, using a Mettler Toledo HPDSC system.
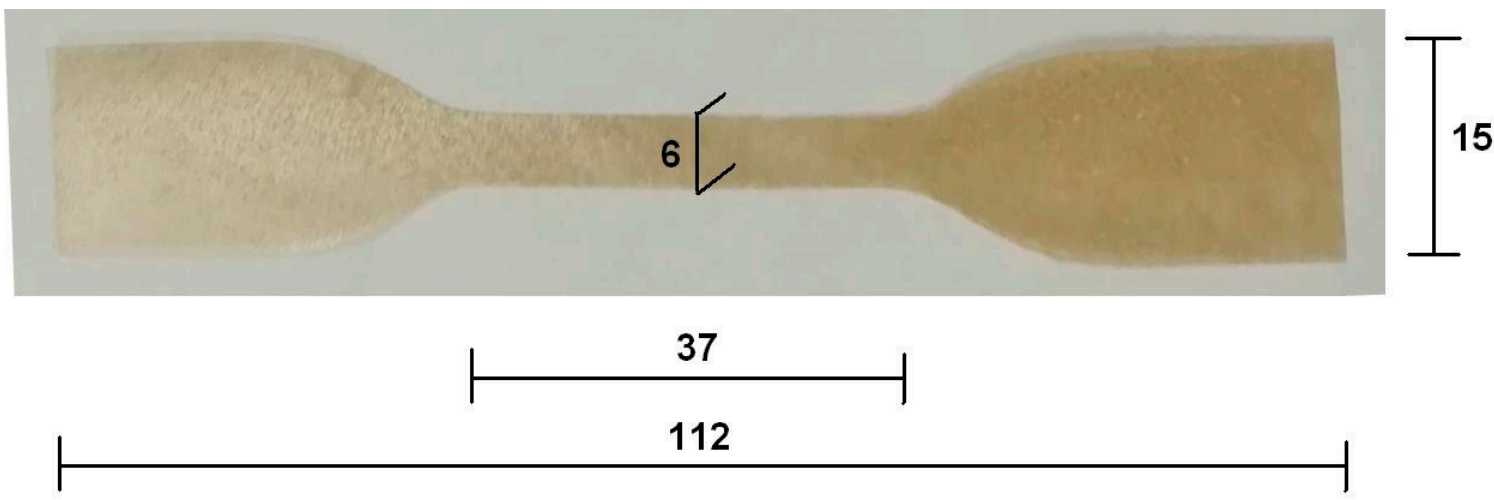

Figure 2. Example of a tensile dog-bone specimen (quotes in $\mathrm{mm}$ with tolerance $\pm 0.1 \mathrm{~mm}$ ).

\section{Results}

To produce the composites, the use of nopal dry fibers to fill them was investigated; their aspect as received is represented in Figure 3a. The fibers were received as complex aggregates of fibrils only partly separated. This would affect the adhesion force of a polymer on it. It was therefore suggested that the fibers would be better ground to a much smaller maximum size in the order of a millimeter or less. It needs to be highlighted, nonetheless, that in this way, proceeding to size reduction via the use of a ball mill, some powder is also obtained, as reported above in Section 2.1. The fibrous material after grinding is depicted in Figure 3b, where its whitish aspect is contrasted against a dark background.

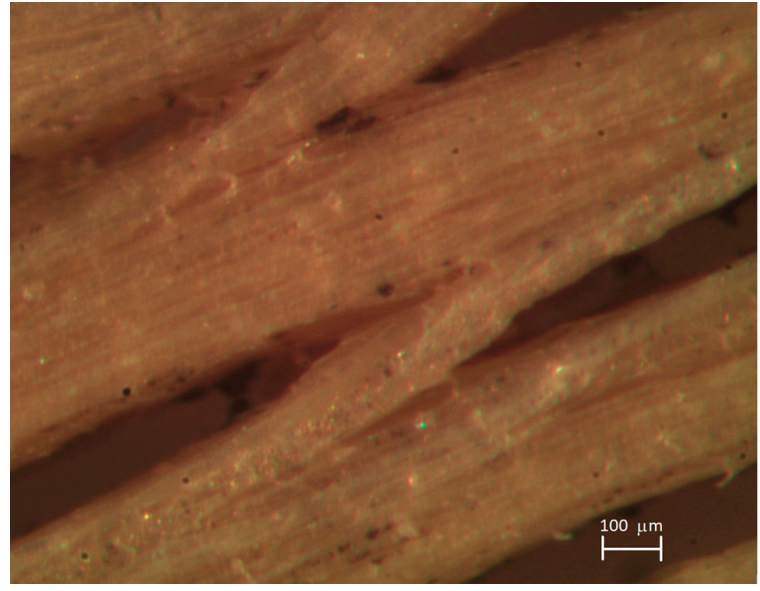

a.

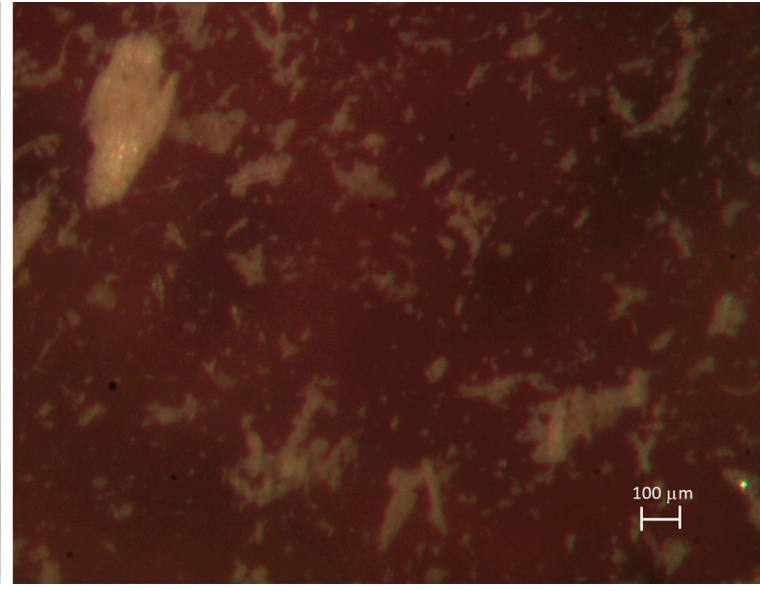

b.

Figure 3. (a) Fibers as received after cleaning; (b) fibers after mashing in ball mill.

The aspect of the samples before and after DSC analysis is reported in Figure 4. A qualitative observation allows reasoning on the fact that the least evidence of changing aspect of the material after DSC is observed in the case of composite B, yet this can also be due to the larger thickness, which 
has been obtained by a longer time mixing, which possibly introduced a larger amount of air in the composite. In the other cases, the color modification due to the temperature cycle is very evident. The respective heat flow curves obtained with temperature increase are reported in Figure 5, where the change in specific heat capacity due to the glass transition phenomenon is not apparent. In thermoplastic starches, glass transition temperature is normally supposed to be between 50 and $70{ }^{\circ} \mathrm{C}$, although with large dependence on the type of starch used and on the amount of glycerol introduced [15]. The first heating cycle, which was performed on the material, did only allow observing a large peak roughly representing its progressive melting. This occurred since there is some previous thermal history of the material, linked to its production, which needs to be eliminated with some thermal cycling to perform a possible measurement of glass transition temperature of TPS. This measurement often proved difficult dealing with TPS blends or composites for its possible superposition with the more obvious peak correlated with melting [16]. The information obtained by this preliminary investigation is useful regardless to suggest whether the introduction of fibers can improve the maximum temperature for use of TPS, which is presently confined at temperatures not above around $50{ }^{\circ} \mathrm{C}$, or not. The data reported in curves in Figure 6 suggest that an increase of melting temperature is only obtained for composites $\mathrm{B}$, where a displacement of around $20^{\circ} \mathrm{C}$ of the heat flow peak from the region of $90-95^{\circ} \mathrm{C}$ to around $115^{\circ} \mathrm{C}$. This is likely to be connected with the larger thickness of the composite, as reported in Table 1, where the effect of the dry nopal fibers in delaying mechanical collapse due to heating applied is visible.

Table 1. Thickness of thermoplastic starch (TPS) and TPS-dry nopal fiber composites.

\begin{tabular}{cc}
\hline Material & Thickness $(\mathbf{m m})$ \\
\hline TPS & $0.125 \pm 0.015$ \\
TPS + FIBERS A & $0.157 \pm 0.013$ \\
TPS + FIBERS B & $0.438 \pm 0.035$ \\
TPS + FIBERS C & $0.156 \pm 0.008$ \\
\hline
\end{tabular}

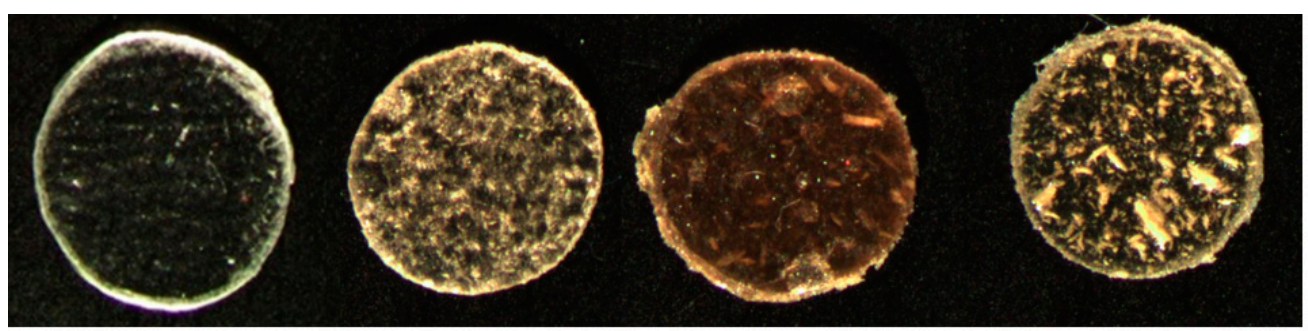

PRE-DSC

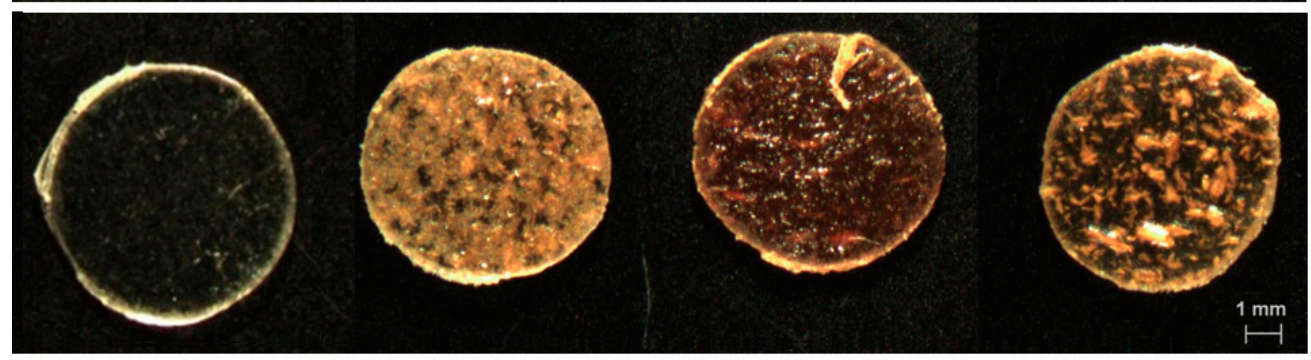

POST-DSC

TPS

A

B

C

Figure 4. Samples of TPS and TPS-dry-nopal composites (type A, B and C, respectively) pre- and post-differential scanning calorimetry (DSC) analysis. 


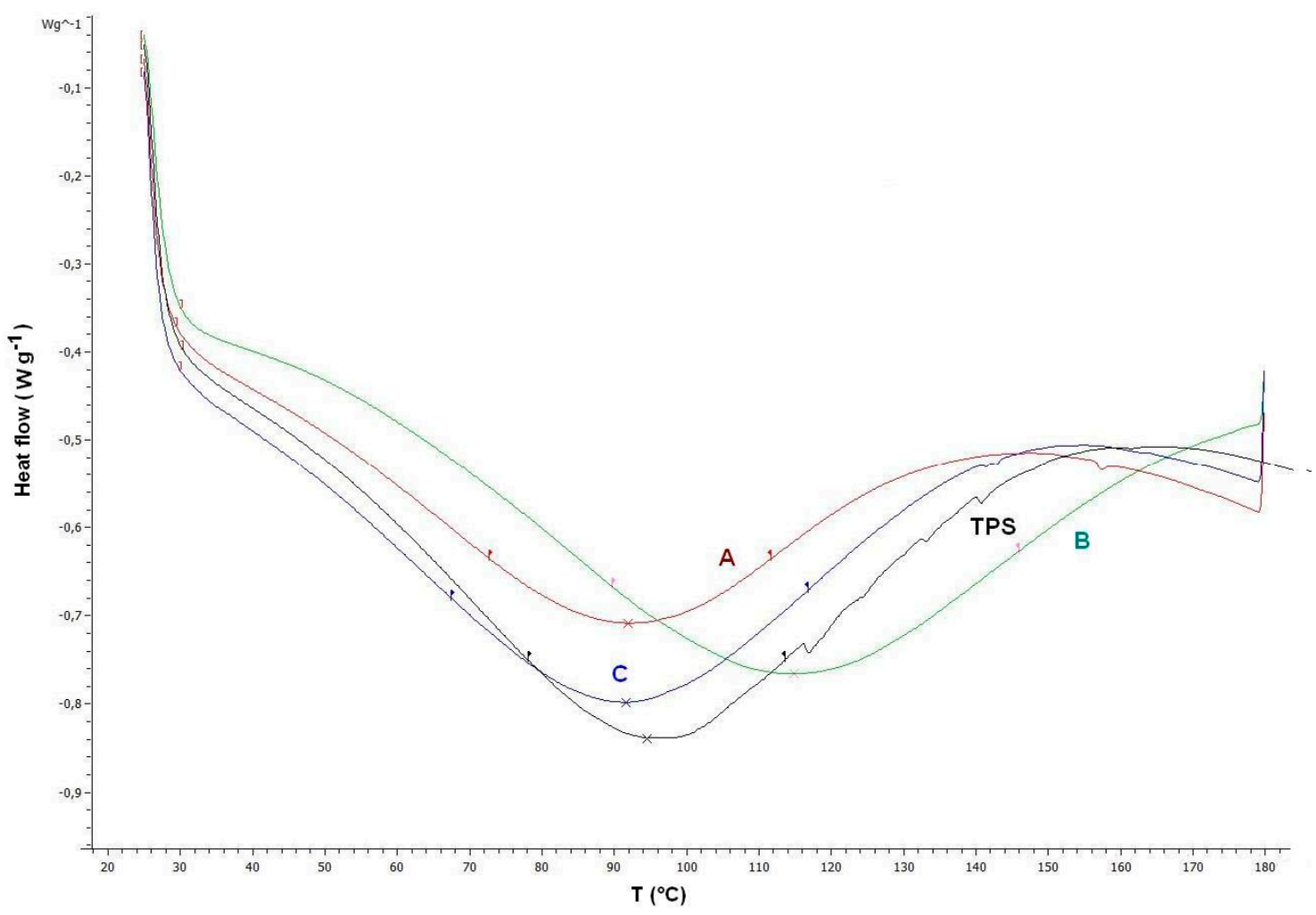

Figure 5. DSC curves for TPS and the three composites with dry nopal fibers (type A, B and C, respectively).
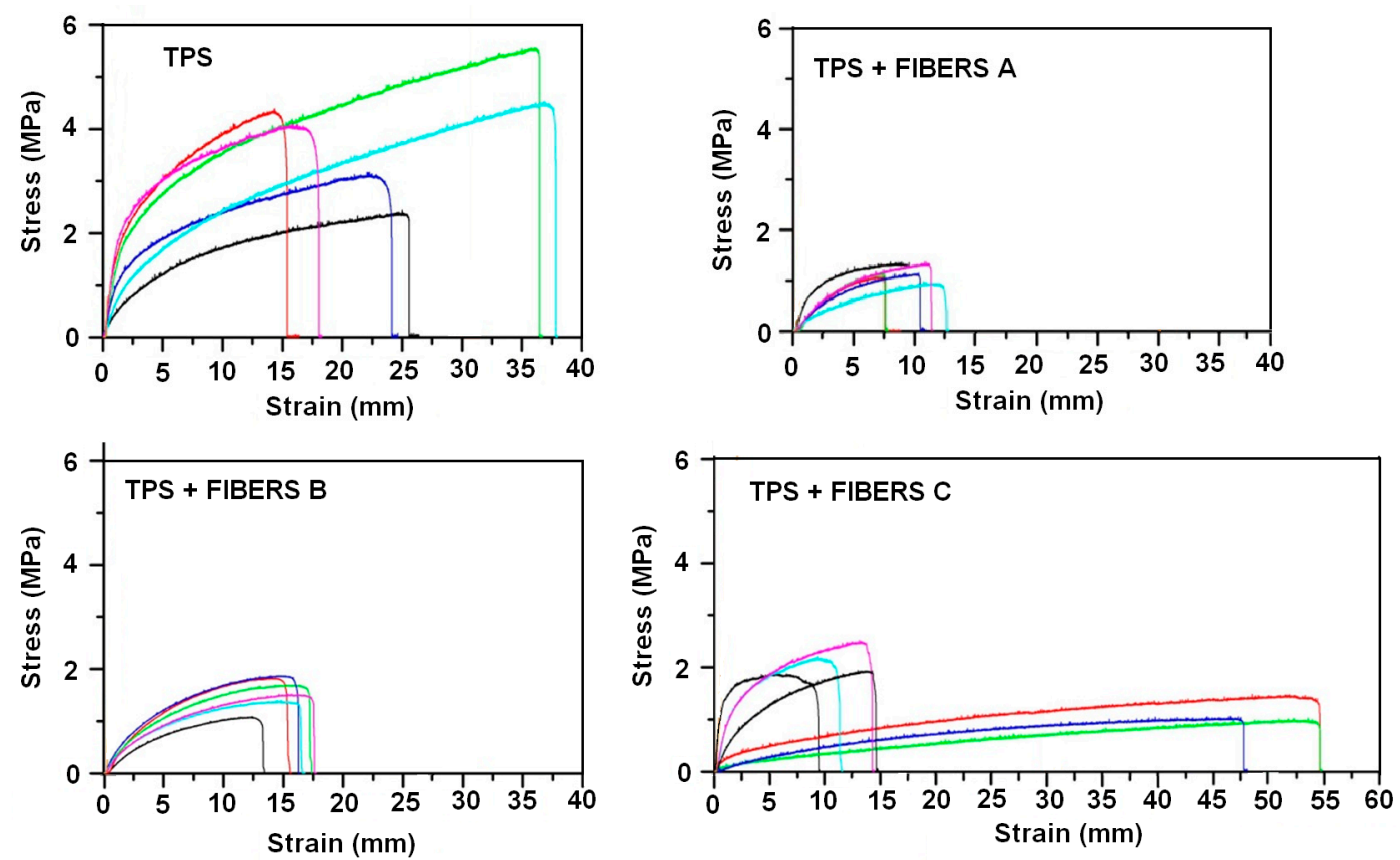

Figure 6. Tensile curves of thermoplastic starch (TPS) and its composites with dry nopal fibers (colors represent the curves for the different samples tested).

As regards tensile characterization, the results showed a considerable decrease in terms of maximum stress as well as maximum strain for all the composites with respect to pure TPS, as reported in Table 2. The single curves obtained sample by sample (not less than 5 samples per series were tested) are shown in Figure 6. This decrease, which leads as a whole to a higher rigidity of the composites, can be attributed to the random distribution and the large dimensional scattering of the dry nopal filler after 
grinding. This situation could be possibly improved in the future either by working on a more effective mixing procedure or by chemically improving the compatibility between the fibers and the polymer; in the case of TPS, the composition could be optimized according to its adhesion with a single fiber once the latter is clearly isolated [17]. It can be observed in particular that in composite C, the variability of strain is very large. This has been attributed to the lower amount of fibers introduced, which therefore gives more importance to the orientation and morphology of the fibers in the composite. It can be also suggested that the use of dry fibers, possibly with different ages of collection, would equally strongly affect the strain of the composite with an effect not negligible in comparison with the one of the amount of plasticizer used, in this case glycerol [18]. Given the evolution of stress-strain curves in the sense of the very limited presence of any really elastic zone, it was considered not very realistic to measure a precise value of Young's modulus, although in general terms, this can be suggested to be in the region of few $\mathrm{MPa}$ and with not very large variations between the three types of composites produced.

Table 2. Tensile tests results for pure TPS and its composites.

\begin{tabular}{ccc}
\hline Material & Max. Stress (MPa) & Max. Strain (\%) \\
\hline TPS & $3.75 \pm 1.16$ & $23.4 \pm 8.3$ \\
TPS-A & $1.06 \pm 0.17$ & $9.2 \pm 1.8$ \\
TPS-B & $1.52 \pm 0.35$ & $14 \pm 1.6$ \\
TPS-C & $1.45 \pm 0.78$ & $17.5 \pm 14.1$ \\
\hline
\end{tabular}

After unloading the materials, the recovery of the final strain was also observed, whose data are illustrated in Table 3. In pure TPS, this was very variable, in some cases leading to the material continuing to elongate after the removal of the load, resulting in a negative strain recovery value. As a whole, the recovery process appeared rather erratic in TPS, due to the simple fabrication process adopted, which represented an obvious limit for the material. Also in composite A, residual deformation was very limited, whereas some residual deformation was observed for the other composites, more predictable for composite B and more variable for composite $C$.

Table 3. Values of post-tensile non-recovered strain for pure TPS and its composites.

\begin{tabular}{cc}
\hline Material & Non-Recovered Strain $\mathbf{( \% )}$ \\
\hline TPS & $-0.4 \pm 1.5$ \\
TPS-A & $0.9 \pm 0.7$ \\
TPS-B & $5 \pm 0.5$ \\
TPS-C & $3.4 \pm 2.5$ \\
\hline
\end{tabular}

Fracture surfaces, reported in Figure 7, highlight that all materials are quite fragile. However, on one side, the fracture of TPS is abrupt and of a totally brittle nature, while some crack deviation is present in composites, due to the insertion of the fibers. In general terms, this process appears more uniform in composite A. On the other side, composite B typically shows also transverse cracks before failure, which is a sign of enhanced rigidity, but on the other side, it may indicate limited toughness, and composite $\mathrm{C}$ tends toward some inflection during loading. The fibrous material was proved to have an apparent density around $0.5 \mathrm{~g} / \mathrm{cm}^{3}$, which was deemed to reduce the TPS one, evaluated to be in the region of $0.95 \pm 0.05 \mathrm{~g} / \mathrm{cm}^{3}$, albeit in a very limited way, due to the small amount of fibers introduced and the variability of the measurements taken. 


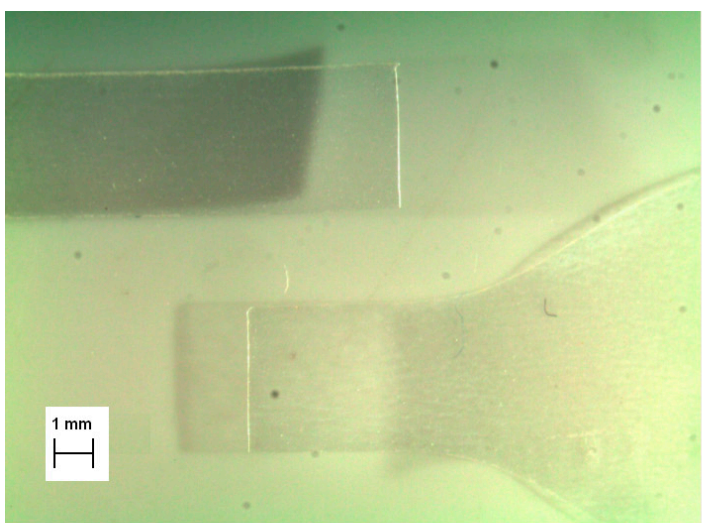

TPS

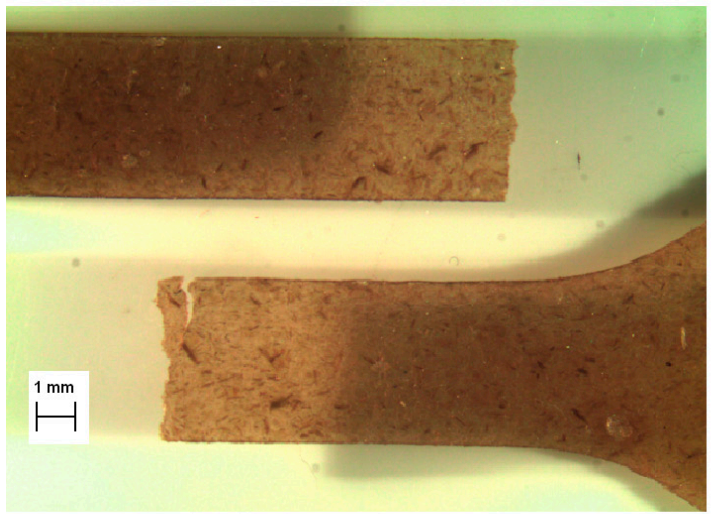

B

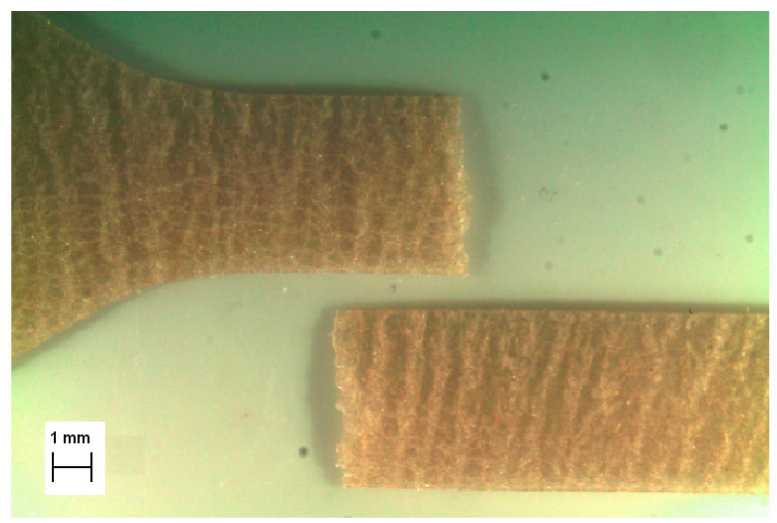

A

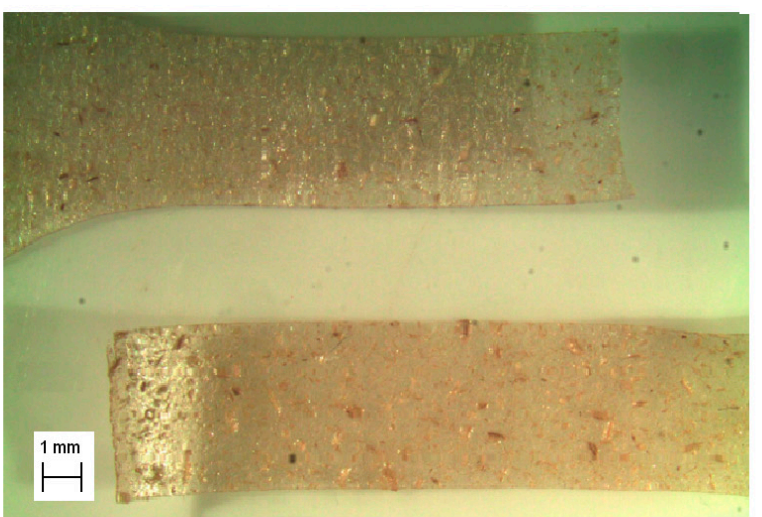

C

Figure 7. Tensile fractured samples of pure TPS and TPS-dry nopal fiber composites (type A, B and C, respectively).

For better insight into the characteristics of the composites, SEM images of the surfaces are offered in Figure 8. With respect to the bare TPS, the composites noticeably show higher porosity, with considerable variability as well. Average porosity value, in all cases higher than $10 \%$ over the surface, does not give significant indications, because voids appear to be concentrated mainly in some critical regions. However, the comparison between the three composites offers some suggestions-in particular, limited mixing time, together with the large amount of fibers generated in composite A, and some separation between TPS and the filler, especially when the latter is in the form of a powder. As a whole, the most compact composite surface is offered by composite B. Energy-dispersive X-ray spectrometry (EDS) analysis suggested that in the surface of composite B, salt deposits are present, which include a number of elements apart from the expected calcium, namely, aluminum, silicon, potassium, iron, and in some cases also titanium. This suggests that the improved mixing allows salts present in nopal fibers to surface. On the other side, it is proposed that some of these elements, which are not typically present in nopal, such as titanium, would need to be verified as regards their presence in soil and possible pollution [19]. The presence of irregularities and cavities is also revealed in composite $C$, where even more elongated nopal fibers show separation problems. 


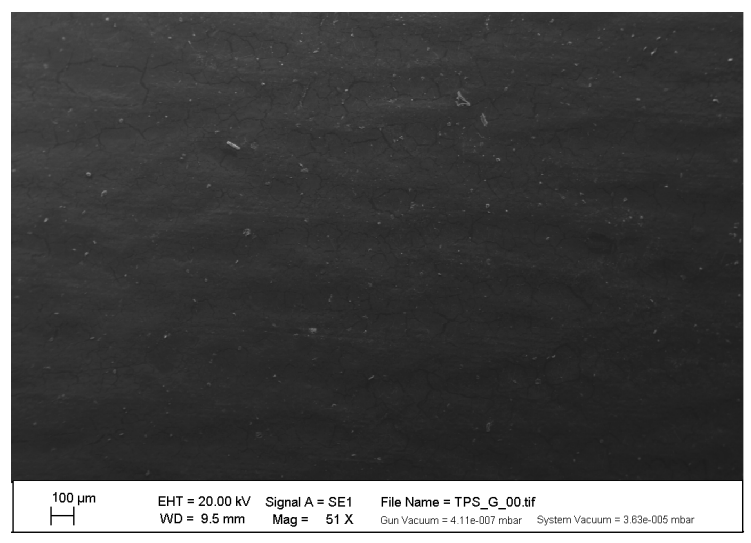

TPS

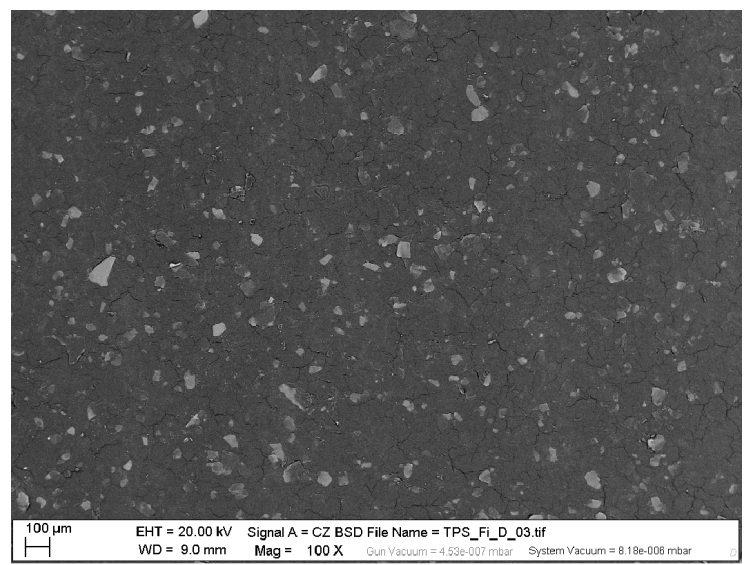

B

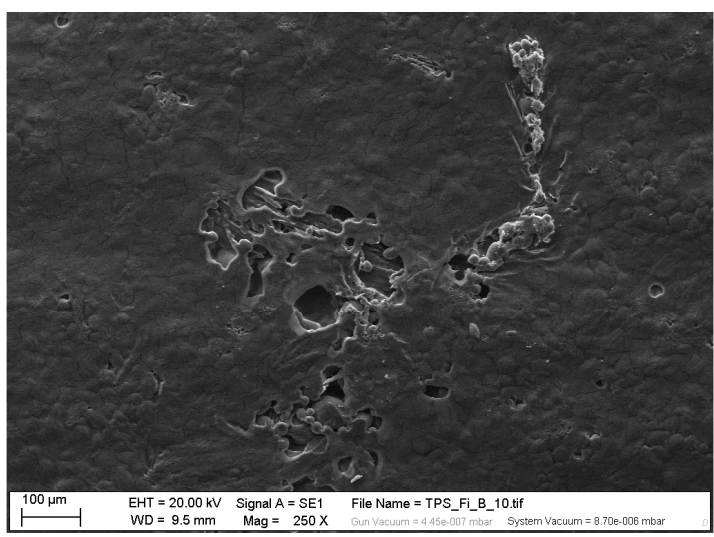

A

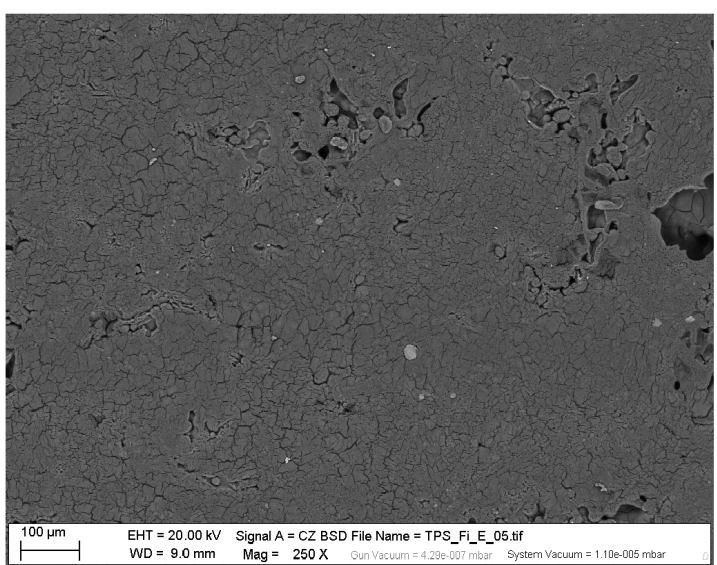

C

Figure 8. SEM images of thermoplastic starch (TPS) and its composites with dry nopal fibers (type A, B and $C$, respectively).

\section{Conclusions}

This preliminary work on the introduction of dry opuntia fibers (maximum amount $16 \mathrm{wt} \%$ ) in an expressly prepared thermoplastic starch (TPS) led to some interesting observations on the possibilities and limits of application of this common garden waste as the filler of a purposely prepared biodegradable polymer.

More specifically, some critical points are observed in terms of possible improvement of fiber mixing so that their addition would not result in a substantial decrease of mechanical properties. On the other side, it is suggested that inserting a considerable amount of fibers in a TPS composite of thickness exceeding a few mm may lead to some improvement in the melting temperature with respect to bare TPS, provided that the mixing before material production is increased.

Future work would need to include the further characterization of opuntia fibers also in terms of their adhesion to the matrix, once inserted in variable morphology and with a very scattered aspect ratio.

Author Contributions: Conceptualization, F.S., G.R., and C.S.; methodology, F.S. and D.M.G.; validation, D.M.G., U.D.A., and F.P.; writing—original draft preparation, F.S.; writing—review and editing, C.S., F.S., and D.M.G.

Funding: The financial support of CARIFAC (Cassa di Risparmio di Fabriano e Cupramontana) is gratefully acknowledged, as regards in particular the PhD grant assigned to Fabrizio Scognamiglio.

Conflicts of Interest: The authors declare no conflict of interest. 


\section{References}

1. Sáenz, C.; Sepúlveda, E.; Matsuhiro, B. Opuntia spp mucilage's: A functional component with industrial perspectives. J. Arid Environ. 2004, 57, 275-290.

2. Ayadi, M.A.; Abdelmaksoud, W.; Ennouri, M.; Attia, H. Cladodes from opuntia ficus indica as a source of dietary fiber: Effect on dough characteristics and cake making. Ind. Crop. Prod. 2009, 30, 40-47. [CrossRef]

3. Curvelo, A.A.S.; de Carvalho, A.J.F.; Agnelli, J.A.M. Thermoplastic starch-cellulosic fibers composites: Preliminary results. Carbohydr. Polym. 2001, 45, 183-188. [CrossRef]

4. Malainine, M.E.; Mahrouz, M.; Dufresne, A. Thermoplastic nanocomposites based on cellulose microfibrils from opuntia ficus-indica parenchyma cell. Compos. Sci. Technol. 2005, 65, 1520-1526. [CrossRef]

5. Greco, A.; Gennaro, R.; Timo, A.; Bonfantini, F.; Maffezzoli, A. A comparative study between bio-composites obtained with opuntia ficus indica cladodes and flax fibers. J. Polym. Environ. 2013, 21, 910-916. [CrossRef]

6. Scognamiglio, F.; Santulli, C.; Roselli, G. Extraction of cellulose nanocrystals (NCC) from cotton waste and morphology of NCC obtained with different alkali neutralization. Curr. J. Appl. Sci. Technol. 2019, 36, 1-8. [CrossRef]

7. Rodríguez-Garcia, M.E.; de Lira, C.; Hernández-Becerra, E.; Cornejo-Villegas, M.A.; Palacios-Fonseca, A.J.; Rojas-Molina, I.; Reynoso, R.; Quintero, L.C.; Del-Real, A.; Zepeda, T.A.; et al. Physicochemical characterization of nopal pads (Opuntia ficus indica) and dry vacuum nopal powders as a function of the maturation. Plant Foods Hum. Nutr. 2007, 62, 107-112. [CrossRef] [PubMed]

8. De Rosa, I.M.; Iannoni, A.; Kenny, J.M.; Puglia, D.; Santulli, C.; Sarasini, F.; Terenzi, A. Poly(lactic acid)/phormium tenax composites: Morphology and thermo-mechanical behavior. Polym. Compos. 2011, 32, 1362-1368. [CrossRef]

9. Troiano, M.; Santulli, C.; Roselli, G.; Di Girolami, G.; Cinaglia, P.; Gkrilla, A. DIY bioplastics from peanut hulls waste in a starch-milk based matrix. FME Trans. 2018, 46, 503-512. [CrossRef]

10. Caliendo, C.; Langella, C.; Santulli, C.; Bove, A. Hand orthosis designed and produced in DIY biocomposites from agrowaste. Des. Health 2018, 2, 211-235. [CrossRef]

11. Santulli, C. Natural Fiber-Reinforced Composites, chapter 12. In Biomass, Biopolymer-Based Materials, and Bioenergy; Verma, D., Fortunati, E., Jain, S., Zhang, X., Eds.; Woodhead Publishing: Cambridge, UK, 2019; pp. 225-238.

12. Sarasini, F.; Fiore, V. A systematic literature review on less common natural fibres and their biocomposites. J. Clean. Prod. 2018, 195, 240-267. [CrossRef]

13. Navya Geethika, V.; Durga Prasada Rao, V.; Mahaboob Ali, S.K.R.S.; Saqheeb Ali, S.K.M.Z.M. Study of tensile and flexural strengths of cocoa and Opuntia fibre reinforced hybrid composites. ASSRG Int. J. Mech. Eng. (SSRG-IJME) 2017, Special Issue May 2017. 291-295.

14. Scaffaro, R.; Maio, A.; Gulino, E.F.; Megna, B. Structure-property relationship of PLA-Opuntia Ficus Indica biocomposites. Composites 2019, 167 Pt B, 199-206. [CrossRef]

15. Forssell, P.M.; Mikkilä, J.M.; Moates, G.K.; Parker, R. Phase and glass transition behaviour of concentrated barley starch-glycerol-water mixtures, a model for thermoplastic starch. Carbohydr. Polym. 1997, 34, 275-282. [CrossRef]

16. Averous, L.; Moro, L.; Dole, P.; Fringant, C. Properties of thermoplastic blends: Starch-Polycaprolactone. Polymer 2000, 41, 4157-4167. [CrossRef]

17. Zhou, Y.; Fan, M.; Chen, L. Interface and bonding mechanisms of plant fibre composites: An overview. Composites 2016, 101 Pt B, 31-45. [CrossRef]

18. Pushpadass, H.A.; Hanna, M.A. Age-induced changes in the microstructure and selected properties of extruded starch films plasticized with glycerol and stearic acid. Ind. Eng. Chem. Res. 2009, 48, 8457-8463. [CrossRef]

19. Hernández-Urbiola, M.I.; Contreras-Padilla, M.; Pérez-Torrero, E.; Hernández-Quevedo, G.; Rojas-Molina, J.I.; Cortes, M.E.; Rodríguez-García, M.E. Study of nutritional composition of nopal (Opuntia ficus indica cv. Redonda) at different maturity stages. Open Nutr. J. 2010, 4, 11-16. [CrossRef]

(C) 2019 by the authors. Licensee MDPI, Basel, Switzerland. This article is an open access article distributed under the terms and conditions of the Creative Commons Attribution (CC BY) license (http://creativecommons.org/licenses/by/4.0/). 